ISSN: 1641-4713; e-ISSN: 2081-1160

DOI: https://doi.org/10.36551/2081-1160.2019.24.33-52

\title{
¿Patrimonios a la carta? Una aproximación a las cocinas patrimoniales desde cuatro restaurantes en Lima
}

\author{
Heritage à la carte? An approach to heritage cuisine from four \\ restaurants in Lima
}

Raúl Matta

Taylor's University, Malaysia

ID ORCID: https://orcid.org/0000-0002-4441-1026

E-mail: raul.matta@taylors.edu.my

Charles-Édouard de Suremain

IRD-MNHN/CIESAS, Francia/México

ID ORCID: https://orcid.org/0000-0001-5547-5781

E-mail: suremain@ird.fr

Recepción: 7.02.2019

Aprobación: 12.09.2019

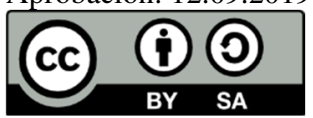

Resumen: Este artículo tiene como objetivo aproximarse a las cocinas patrimoniales desde la mirada de quienes lo sustentan y promueven a diario. Nuestro enfoque se desmarca de las visiones más institucionales del patrimonio alimentario, aquellas impulsadas por los gobiernos, promotores culturales, agentes económicos y organismos internacionales como la UNESCO. Tomando como ejemplo cuatro restaurantes de distinta gama en la ciudad de Lima, mostraremos cómo chefs, cocineros y restauranteros proponen y ejecutan versiones "ordinarias" del patrimonio alimentario y como éstas se rigen por el uso de representaciones, valores y jerarquías relacionados con sus historias individuales y proyectos de vida. Estas cocinas patrimoniales se caracterizan por permitir modos de creación flexibles y acordes a las capacidades y necesidades de quienes manejan negocios culinarios y gastronómicos. En suma, veremos que estas cocinas estimulan una visión del patrimonio alimentario más arraigada en los desafíos cotidianos y futuros que en el pasado y en concepciones predeterminadas de la cultura.

Palabras clave: patrimonio alimentario, restaurantes, cocinas patrimoniales, cultura alimentaria, Perú. 
Abstract: This article aims to approach heritage cuisines from the perspective of those who sustain and promote it on a daily basis. Our focus differs from the most institutional views of food heritage, those promoted by governments, cultural promoters, economic agents and international organizations such as UNESCO. Taking as an example four restaurants of different types and status in the city of Lima, we will show how chefs, cooks and restaurateurs propose and perform "ordinary" versions of food heritage and how these are ruled by the use of representations, values and hierarchies related to their individual histories and life projects. These heritage cuisines are characterized by allowing flexible ways of creation in accordance to the capacities and needs of those who run culinary and gastronomic businesses. In short, we will see that these cuisines prompt a view of food heritage as much more entrenched with the day-to-day and future challenges, than with the past and predetermined conceptions of culture.

Keywords: food heritage, restaurants, heritage cuisines, food culture, Peru.

\section{ENTRADA: EL RESTAURANTE Y EL PATRIMONIO ALIMENTARIO ${ }^{1}$}

Es interesante notar junto con otros académicos que en los estudios sobre la comida y la alimentación - cuyo número, por cierto, no deja de crecer - el restaurante ha recibido hasta el momento una atención marginal (Beriss, Sutton, 2007; Hassoun, 2014). Las ciencias sociales han fijado su atención en temas como la globalización de la comida y las cocinas (Bestor, 2004; Pilcher, 2012), las cocinas nacionales y el nacionalismo culinario (DeSoucey, 2010; Ferguson, 2010; Matta, 2014; Ichijo, Ranta, 2016), los procesos de identificación, desterritorialización y territorialización de prácticas y productos alimentarios (Trubek, 2008; May, Sidali, Spiller, Tschofen, 2017; Parasecoli, 2017), el turismo gastronómico (Long, 2004; Timothy, 2015; Medina, Leal, Vázquez-Medina, 2018) y, tema de este número especial, el patrimonio alimentario (Tibère, Bessière, 2011; Brulotte, Di Giovine, 2014; Bak-Geller, Matta, Suremain, en prensa). El interés en todos estos temas es importante, justificado y necesario pues la irrupción de la "alimentación" en las arenas política y cultural a nivel global es relativamente reciente y bastante vigorosa. Lo que sorprende es la escasa presencia del restaurante en los debates sobre el patrimonio alimentario y las llamadas "cocinas patrimoniales" (heritage cuisines) (Timothy, 2015) - para algunas excepciones, ver Brulotte y Starkman (2014), Matta (2013) y Sammells (2014). Es curioso por ejemplo que, en una reflexión sobre las relaciones entre cultura alimentaria, patrimonio y turismo (Medina, 2017) la palabra "restaurante" no aparezca, o que apenas sea

\footnotetext{
${ }^{1}$ Esta investigación fue posible gracias a una Acción Incitativa, concedida por el Instituto de Recherche pour le Développement (IRD) en el año 2008, y al financiamiento de la Agence Nationale de la Recherche en el marco del proyecto FoodHerit (ANR-13-CULT-0003) desarrollado entre 2013 y 2017.
} 
mencionada en un estudio compilatorio sobre los usos y significados de la comida en Iberoamérica (López-García, Mariano Juárez, Medina, 2017). Sin embargo, sabemos dónde los turistas van a comer, y no es precisamente a la calle, a los mercados o las casas de los habitantes - aunque también y cada vez con más frecuencia (Caldwell, 2011; Henderson, Si Yun, Poon, Biwei, 2012; Hernández, Andreeva, 2016) - pero sí a los restaurantes. El restaurante probablemente sea el espacio que, junto con las cocinas de los hogares, ofrece una mejor vitrina al patrimonio alimentario, ya que es allí donde los cocineros negocian los gustos y las tradiciones culinarias junto con (o a pesar de) sus comensales. Es también allí donde se alzan y se derriban las fronteras de las cocinas nacionales, regionales, locales o "étnicas" y donde se producen los exotismos y cosmopolitismos culinarios (Hassoun, 2010; Ray, 2016). En suma, las culturas alimentarias cobran mucho de su significado en el restaurante. Sin embargo, parece que el peso creciente de la patrimonialización en las políticas culturales y comerciales de los Estados, así como en las actividades de los sectores del turismo, la agroindustria y el desarrollo rural ha volcado el interés de las ciencias sociales más hacia el estudio de construcciones sociales y "tradiciones inventadas" (Hobsbawn, Ranger, 1983) alrededor de la alimentación que hacia las expresiones del patrimonio alimentario en sus formas más tangibles y cotidianas.

En los restaurantes se seleccionan, interpretan y valorizan (materialmente y simbólicamente) alimentos, ingredientes y conocimientos culinarios locales y foráneos; y es durante estos procesos que se negocia el valor económico, cultural y patrimonial de las cocinas. La expansión del mercado gastronómico a nivel global, el activismo alimentario (como el que promueve el movimiento Slow Food) y el auge de las narrativas de identidad, autenticidad y terroir en las industrias restaurantera y turística allanan el camino para que las cocinas pongan a prueba su versatilidad y estimulen la competencia entre tendencias culinarias nuevas y establecidas. Los restaurantes son, cada vez más, espacios donde cocineros y chefs plasman ideas alrededor de la tradición en cocinas que llamaremos patrimoniales, apoyándonos sobre un uso del término patrimonio más como noción que como concepto. En ese sentido, no adoptamos definiciones institucionales del patrimonio cultural en general y del patrimonio alimentario en particular, como aquellas promovidas por la UNESCO y los gobiernos, mayormente enfocadas a objetivos de diplomacia cultural, marketing territorial y desarrollo a través del turismo (Matta, 2016; 2019). Nos referimos, más bien, a elementos y repertorios de acción de la actividad culinaria que remiten a una idea de patrimonio alimentario más flexible, versátil, cotidiana e informal. Las cocinas patrimoniales 
hacen referencia a ingredientes, prácticas y saberes culinarios localizados, (más o menos) arraigados en el tiempo y vinculados a la historia social de grupos humanos diversos (naciones, regiones, colectividades, clases sociales, diásporas, etc.). En tiempos en que la diferencia cultural es considerada como mercancía (Comaroff, Comaroff, 2009), las cocinas patrimoniales deben ser entendidas como proyectos económicos alrededor de elementos culturales delimitados e identificados como valiosos tanto para quienes las ofertan como para quienes las consumen. Estas cocinas están determinadas por los conocimientos, capital, expectativas y ambiciones de los productores y de los clientes. Algunas dan lugar a tendencias gastronómicas a la vez elitistas y "étnicas" como la "nueva cocina nórdica", la cocina "nuevo latino" y la "cocina novoandina", que son el resultado de abundantes recursos, tangibles e intangibles, y discursos que se nutren de la globalización y el cosmopolitismo, pero al mismo tiempo los desafían (Fonseca 2005; Matta 2013; Tholstrup Hermansen 2012). Otras cocinas construyen su especificidad, localidad y relevancia sobre el registro de la familiaridad o la cotidianeidad, la practicidad, la estabilidad y la seguridad. Estas están más cerca de lo que comúnmente conocemos como "cocinas tradicionales".

El contexto peruano, y limeño en particular, es especialmente pertinente para estudiar la relación entre cocina y patrimonio desde el restaurante. Desde hace 15 años, el Perú vive un boom gastronómico. El interés generalizado por la cocina peruana "tradicional" y sus variantes más modernas y cosmopolitas dio lugar a que las relaciones entre cocina, identidad y política sean explotadas por actores públicos y privados de distinto orden y con diferentes intereses. Si bien se puede afirmar que se trata de un fenómeno global, el caso peruano es paradigmático. La cocina peruana ha sido designada patrimonio cultural de la nación por el gobierno peruano, patrimonio cultural de las Américas por la Organización de Estados Americanos, y cumple casi el mismo rol que Machu Picchu en la atracción de turistas. En el Perú se estima a más de 80.000 el número de jóvenes estudiando para cocineros en más de cien escuelas de cocina; a dos platillos y a un cóctel se les ha adjudicado un día nacional conmemorativo; y un conocido chef, Gastón Acurio, fue anunciado durante meses como candidato presidencial. Por último, pero no menos importante, estadísticas oficiales de 2014 contabilizan cerca de 40000 restaurantes en Lima Metropolitana (INEI, 2014). Inmerso en un giro gastropolítico (Matta, García, 2019), el Perú se presenta hoy ante el mundo como una nación culinaria (food nation) que busca capitalizar en el arraigo de un discurso que presenta a la "cocina peruana" como un motor de desarrollo incluyente y como un proyecto de sociedad unificador y consensual. Ideas sobre la comida 
como patrimonio, o como un "bien común" de los peruanos, permean la sociedad entera.

Este artículo tiene como objetivo plantear interrogantes con respecto a los criterios de construcción patrimonial. Al analizar el trabajo de cocineros y restauranteros, nuestro enfoque se desmarca de las versiones más institucionales del patrimonio alimentario. Tomando como ejemplo cuatro restaurantes de distinta gama en la ciudad de Lima, mostraremos cómo chefs, cocineros y restauranteros proponen y ejecutan versiones "ordinarias" (Isnart, 2012) del patrimonio alimentario - sin necesariamente expresarlas formalmente en términos de patrimonio y como éstas se rigen por el uso de representaciones, valores y jerarquías relacionados con sus historias individuales y proyectos de vida. Los cuatro restaurantes están ubicados en el distrito de Miraflores, un distrito vibrante y mixto donde reside la clase media y media-alta de Lima y que constituye uno de los principales nodos comerciales y turísticos de la ciudad. La oferta culinaria en Miraflores es múltiple y diversa: el distrito alberga desde los restaurantes más exclusivos del país hasta locales muy modestos que alimentan a oficinistas y taxistas. Realizamos observaciones en los restaurantes y entrevistas con cocineros y restauranteros entre los años 2007 y 2015. Como complemento efectuamos un seguimiento de la evolución de estos locales hasta hoy, mediante visitas a sus respectivos sitios web y lectura de artículos de prensa y opiniones de blogueros. En lo que sigue demostraremos que, lejos de suscitar estandarización y ejercer un poder coercitivo en nombre de la tradición o de alguna supuesta esencia cultural, la relación de las cocinas con el patrimonio alimentario se caracteriza por permitir modos de creación flexibles y acordes a las capacidades y necesidades de quienes manejan negocios culinarios y gastronómicos. En suma, veremos que la puesta en práctica del patrimonio alimentario tiene mucho más que ver con el día a día y el futuro que con el pasado y concepciones rígidas de la cultura.

\section{Plato DE FONDO: CUATRO RESTAURANTES}

\section{La fonda de Pedro}

Pedro nació en un pueblo pequeño dedicado a la horticultura, situado a unos cincuenta kilómetros al norte de la ciudad de Lima. Sus padres eran jornaleros precarios y sus abuelos campesinos quechua-hablantes sin tierra, que migraron de la sierra a la costa. Pedro fue a la escuela hasta los catorce años, después viajó a la capital para trabajar. Su esposa creció en un barrio pobre de Lima. Ella logró 
terminar la escuela secundaria y estudió contabilidad durante dos años. Pedro ocupó todos los cargos posibles en la restauración, casi siempre en restaurantes chinos y "chifas" (restaurantes que sirven adaptaciones locales de la cocina cantonesa): fue limpiador, friegaplatos, camarero y auxiliar de cocina hasta llegar a ocupar la plaza de cocinero. Pedro cuenta que ahorró cada céntimo hasta el año 1990, en el que invirtió su dinero y el de su esposa en el alquiler del primer local en el que sirvieron comida. Gracias a la coyuntura económica relativamente estable del país, él y su esposa compraron en el año 2000 un pequeño local en Miraflores. Para Pedro no hay nada que equivalga a su experiencia práctica de la restauración. Con el apoyo de su esposa, dice que "hace de todo y controla todo" en su pequeño restaurante, que corresponde mejor a la definición de fonda.

Bien establecida en el barrio, la fonda de Pedro atrae a una clientela compuesta mayormente por oficinistas de rango bajo y medio que acuden cada mediodía en pequeños grupos. A estos se suman empleados públicos de igual rango y choferes de taxi. La decoración del local es sencilla; las mesas y las sillas de madera están distribuidas en un patio descubierto protegido por un toldo. El comedor da directamente a la calle. La cocina está separada del comedor por una pared y los platos pasan de un lugar al otro por una pequeña apertura o ventana cuadrada. Pedro y su esposa se encargan del servicio. La fonda se parece a muchas otras existentes en la capital; para llegar a ella hay que conocerla previamente o encontrarla por azar, ya que ningún cartel anuncia su existencia. Tampoco tiene nombre. Sólo tres tablones colgados hacia la calle indican las tres opciones (menús) del día. Cada una ofrece una estructura y un contenido con poca variedad, por un precio modesto y fijo. El menú "Criollo", el de "Mariscos" y el "Chifa" se componen de un entrante, un plato combinado (llamado "segundo"), un postre y agua de frutas. Existe la posibilidad de encargar un plato único, pero cuesta prácticamente lo mismo que la opción completa, unos 10 soles (poco más de 2 euros).

En la cocina trabaja en hombre de origen chino, que convenció a Pedro para que cambiase el menú "Ejecutivo" (que en este tipo de locales designa un menú un poco más sofisticado que los otros ofrecidos) por el menú "Chifa". Al cocinero le ayuda un joven de veinte años, sobrino de la esposa de Pedro. La mujer nunca abandona el local, y siempre se mueve entre el comedor y la cocina. Como Pedro, ella sirve los platos y empaqueta las comidas para quienes optan por no comer en el lugar. El hecho de que la esposa sirva la comida le da al lugar un cierto ambiente familiar, probablemente porque pone en escena una imagen o un rol de la mujer bastante presente en las clases populares: el de la madre que vela por la salud y atención de los miembros del hogar. Sin embargo, la esposa de Pedro juega 
también un papel en las finanzas del negocio: lleva la libreta de cuentas donde se anotan el número de menús vendidos. Pedro y su esposa acuden en taxi al Mercado Central tres veces por semana para abastecerse, y afirman que sólo compran a los vendedores que conocen. De regreso a la fonda, lavan, cortan y envasan los ingredientes, que luego reparten entre un congelador grande y dos neveras. Cocinados en grandes cantidades, los platos se preparan siempre por la mañana: "Los platos tienen que ser frescos y recordar a lo que se come en casa; aquí se come lo tradicional", dice Pedro.

\section{Centolla}

Alberto Sueyoshi llegó al Perú hace unos cuarenta años desde la isla de Okinawa, en Japón. Trabajó primero contratado por una empresa alimentaria japonesa (Ramen) y, a continuación, para la embajada de su país. Después de casarse con una hija de inmigrantes japoneses, decidió instalarse definitivamente en el Perú. En 2007, junto a su hijo Ricardo, abren el restaurante Centolla. A Centolla se le podría considerar como un establecimiento al que le habría gustado codearse con los grandes restaurantes de Lima. Situado en una calle concurrida de Miraflores, en un barrio rodeado de comercios y oficinas, el restaurant propone una carta que apuesta por el producto estrella que le da el nombre: la centolla (Lithodes Santolla). En uno de nuestros encuentros, Sueyoshi hijo desveló que quería consolidar el prestigio de su restaurante gracias a este crustáceo, muy apreciado por ser grande, sabroso y escaso. La centolla o king crab sólo se pesca en los mares de Alaska, de Rusia, del Pacífico sur (Patagonia) y, últimamente (desde inicios de los 2000), en las profundidades del mar peruano, por debajo de los mil metros.

En cuanto al diseño y decoración del lugar, Centolla entra dentro de las "convenciones" de un establecimiento de rango medio o medio-alto. Es decir, sigue las tendencias estéticas que utilizaron en su momento los restaurantes de mayor prestigio: preferencia por las formas geométricas y todo lo que no sea recargado, propio del minimalismo en arquitectura y en diseño. A la oferta gastronómica de Centolla se le puede calificar de convencional, ya que se apoya en el éxito de la "cocina fusión" - corriente nacida en California, Estados Unidos, en los años 1970 que consiste en combinar sabores e ingredientes de todo el mundo. La novedad que representó este tipo de cocina a inicios del boom gastronómico peruano, allá por mediados de los 2000 , se convirtió por efecto de moda en moneda corriente y, por ende, en una apuesta segura para los restauranteros. En Centolla 
la fusión toma forma de makis o rolls ${ }^{2}$, interpretados a la usanza californiana y mediante el uso de materias primas que se encuentran en Perú. Estas preparaciones tienen un gran éxito en los restaurantes de Lima, principalmente entre quienes están acostumbrados a la versión globalizada de la cocina japonesa. Se podría afirmar entonces que lo único novedoso de la propuesta de Centolla es la presencia del preciado crustáceo en los diferentes apartados de la carta.

Efectivamente, los restauranteros no disponen de otros elementos que les permitan diferenciar Centolla de los restaurantes que se dirigen a la clientela que frecuenta el barrio: ejecutivos y asalariados de rango medio a la hora de almorzar y un público más heterogéneo a la hora de la cena. Los Sueyoshi reconocen la desventaja que implica no tener en su cocina a un gran chef o cocinero mediático. Esta limitación los llevó a emprender esfuerzos de comunicación. Lo primero era sacar la centolla del anonimato. Este crustáceo sigue siendo un gran desconocido en Lima, a pesar de la oferta considerable de pescados y mariscos en las mesas de la capital. Y peor aún es que, en el universo gastronómico americano, las centollas más conocidas son las de Chile - rival simbólico e histórico de Perú en varios aspectos -, donde se consumen con mayor frecuencia. Por consiguiente, fue primordial dar a conocer las virtudes del crustáceo peruano marcando la diferencia con el de Chile. La centolla peruana es, según cuenta el dueño más joven, "más grande, carnosa y sabrosa". Asimismo, los propietarios tuvieron que "legitimar" su carta, en la medida en que sus cocineros no dominan los códigos del discurso gastronómico ni disponen de competencias mediáticas. Tampoco los Sueyoshi disponen de conocimientos y medios económicos para desarrollar una estrategia comercial que le permita al restaurante acceder a una categoría más alta.

Para paliar estas carencias, los dueños de Centolla organizan comidas a las que se invita a "líderes de opinión" para que conozcan el lugar, degusten los platos y los comenten. La "teoría de las dos etapas de la comunicación" desarrollada por Katz y Lazarsfeld (1955) define a los líderes de opinión como personas que, por su estatus o posición social, influyen sobre la opinión de su entorno. Según cuenta uno de los invitados a estas comidas, la composición de los invitados depende menos de los conocimientos culinarios de estos que de su condición de clientes potenciales. A estas comidas también son invitados críticos y periodistas gastronómicos, que no siempre acuden. La opinión informal de estos comensales, representantes de profesiones liberales (abogados, médicos, etc.), cuadros de

\footnotetext{
${ }^{2}$ El makisushi, popularmente conocido como maki, es una especialidad culinaria japonesa que se presenta en forma de rollo de algas secas nori, que envuelven arroz al vinagre, y relleno de varios alimentos, en concreto de pescado crudo u hortalizas.
} 
empresas y diplomáticos se convierten en herramientas indispensables para estructurar la oferta del restaurante y, a la vez, comunicarla al exterior, hacia sus círculos de influencia. Los dueños esperan que la intervención de estas personas influyentes les ayude a construir el prestigio del local.

Mientras tanto, para sobrevivir, Centolla se aferra a la cocina fusión peruanojaponesa, más conocida como nikkei ${ }^{3}$, que coincide con los orígenes de sus dueños. En las bandejas de makis conviven variedades "fusión” ya establecidas como el Furai Maki (maki empanado relleno de langostinos, aguacate y queso fresco cubierto de salsa teriyaki) o el Hotate Maki (relleno de pescado empanado y aguacate, y envuelto de carpaccio de vieira espolvoreado con parmesano y cubierto de salsa teriyaki), y elaboraciones más recientes y "peruanizadas" como el Huancaina Roll (relleno de pescado, aguacate y queso fresco y cubierto de salsa huancaina $^{4}$ ) y el Acebichado Roll (relleno de langostinos, aguacate y queso fresco envuelto de carpaccio de pescado crudo y cubierto de una salsa de zumo de cebi$c^{5}{ }^{5}$ ). Sin embargo, la fusión peruano-japonesa no es la única cocina que practica el chef Daniel (también descendiente de japoneses): "Esto es un tacu-tacu ${ }^{6}$ de pez espada en salsa de $\operatorname{seco}^{7}$. ¿Y por qué este plato? En realidad, es porque somos peruanos. Puede que sea un chinito [puede que tenga los ojos rasgados...] pero somos peruanos, ésta es nuestra cultura y en nuestra carta también tenemos platos totalmente peruanos. Este plato es una especie de fusión peruana, ya que lleva tacu-tacu, la salsa de seco a la norteña (salsa de cilantro "a la manera del norte de Perú"), que contiene zapallo loche ${ }^{8} .$. También tiene cilantro picado en lugar de cilantro molido, y pescado en lugar de carne". 9 A continuación, el chef asegura que el plato arriba descrito es una creación colectiva del equipo de cocina, ya que todos dieron opiniones y sugerencias. Por ello lo califica como una "fusión al cuadrado".

\footnotetext{
${ }^{3}$ Término que designa las personas de origen japonés, y su descendencia, que han emigrado o viven en el extranjero. En el entorno gastronómico peruano, "nikkei" se refiere indefectiblemente a la fusión peruano-japonesa o, más precisamente, a la asimilación de técnicas y de ingredientes japoneses por parte de cocineros peruanos. Ver, por ejemplo, el video de la presentación del libro Nikkei es Perú (Tsumura, Barrón, 2013), http://vimeo.com/74262785.

${ }^{4}$ Salsa de origen andino a base de queso fresco y pimiento amarillo peruano.

${ }^{5}$ Plato frío de pescado blanco crudo cortado a dados, marinado en zumo de limón y mezclado con finas láminas de cebolla roja cruda, sal y pimiento.

${ }^{6}$ Masa a base de frijoles y arroz rehogada en aceite.

${ }^{7}$ Salsa a base de cilantro.

${ }^{8}$ Variedad de calabaza cultivada en la costa norte de Perú.

${ }^{9}$ Declaraciones extraídas de http://www.youtube.com/watch?v=-qXNo0R11kE
} 


\section{Pe(s)cados capitales}

Nguyen "Alejandro" Chávez proviene de la clase media local por parte de padre y de una familia de origen asiático por parte de madre. De ahí uno de sus nombres, Nguyen, que no utiliza porque prefiere el de Alejandro. Después de una educación en los mejores colegios de Lima, realizó estudios de antropología y obtuvo la licenciatura. Entretanto conoció a su esposa, Sue Cang-Say, cuyos padres son de origen chino. Desde hace varias generaciones, la familia de Sue posee $\mathrm{y}$ alquila hangares para almacenamiento en la provincia portuaria de Callao y otras zonas cercanas al litoral de Lima. Alejandro empezó como restaurantero cuando contrajo matrimonio. En el año 2000, sus suegros le regalaron uno de sus hangares, situado cerca de la urbanización Santa Cruz, en Miraflores. Ese hangar se transformó en restaurante. Santa Cruz era hasta ese entonces una zona de talleres mecánicos, tiendas de repuestos y almacenes considerada insegura; algo así como el lado sombrío de Miraflores. Sin embargo, políticas municipales alentaron la desaparición progresiva de estas actividades en la zona y atrajeron negocios más selectos y un público con mayor poder adquisitivo (sobre gentrificación y el boom gastronómico, ver Consiglieri, 2019). Alejandro y su familia se beneficiaron con ese cambio.

Sue se encarga de la gestión económica del negocio, mientras su esposo se ocupa de todo lo demás. Alejandro afirma que sus conocimientos en antropología le ayudaron a desarrollar el concepto y diseño del restaurante, así como una organización del trabajo que califica como "una experiencia participativa" y sobre la que nos detendremos más adelante. El restaurante, de diseño minimalista, pulido y sobrio, desentonaba con la austeridad del barrio, anterior a su gentrificación. Los comedores pueden acoger hasta doscientos comensales a cuyo servicio están destinados una quincena de camareros, otra de auxiliares de cocina y un chef que se formó en una escuela de cocina supervisada por el célebre Gastón Acurio. Alejandro dice conocer a Acurio, pero no comulga con su estilo de cocina.

El precio de los platos es difícilmente accesible para la mayoría de peruanos. La tarjeta de crédito es un medio de pago común en el local. Aproximadamente unos sesenta platos conforman la carta, cuyos precios oscilan entre los cuarenta y ochenta soles (entre diez y veinte euros). La oferta de bebidas es variada pero común en ese tipo de restaurantes: uno puede elegir entre cócteles, cervezas y vinos internacionales. La especialidad es la cocina de mar. En las guías gastronómicas, el restaurante se encuentra en el apartado "pescados y mariscos". Su originalidad reside en que los platos representan los siete pecados capitales de la 
religión católica. De ahí el nombre del restaurante: Pescados Capitales. La carta ofrece al comensal experimentar pecados viejos y nuevos, entre ellos: Infidelidad (pez espada a la parrilla), Trabajolismo (paiche ${ }^{10}$ hiperactivo), Intolerancia (chita ${ }^{11}$ acriollada), Santa Ira (pulpo adolescente a la parrilla), Lujuria freudiana (calamares bebé a la parrilla) y Soberbia (risotto a la Bonaparte). Los juegos de palabras continúan: los "Pecaítos de la casa" son los postres y los precios se calculan en Penitencias ${ }^{12}$. Platos a base de risotto y curry como Pasividad (risotto de arroz arbóreo mezclado con dos variedades de quinua en una crema de pimiento y tabasco, coronado con mariscos marinados en curry a la parrilla), así como el uso de wok y la parrilla, indican claramente un componente "fusión" en la carta.

Alejandro afirma que él mismo se encarga de ir al puerto al amanecer para abastecerse. Sólo trabaja con algunos pescadores y compra productos de temporada. Una vez al mes organiza una sesión de trabajo con su equipo de cocina en la que se discuten, suprimen, añaden o modifican las recetas. Las reuniones se llevan a cabo en una sala detrás del comedor. La cocina contigua permite poner en práctica las sugerencias de unos y otros. Los camareros también participan en las discusiones. Para Alejandro, la opinión de todos los empleados es importante. Les pide que se pongan en el lugar de los clientes para poder acceder a "su opinión real", es decir, a puntos de vista que quizás no harían explícitos delante de él en otro contexto. Le interesa conocer la opinión de los camareros pues los considera representantes de las clases populares y esto ayuda, dice, a que su cocina sigue siendo "asequible". El trabajo participativo para definir la carta conforta la idea de Alejandro de que la alta cocina peruana tiene que ser de alguna manera una "cocina popular, es decir, una mezcla de sabores, texturas, gustos y olores que se inspira en la cocina de la gente sencilla". Es, continúa, la manera de "comer de verdad y disfrutar de lo mejor de la tradición".

\section{Huaca Pucllana}

El elegante restaurante Huaca Pucllana abrió sus puertas en 2001, dentro del complejo arqueológico del mismo nombre. Huaca es el término quechua para designar un lugar sagrado y de culto. La Huaca Pucllana está ubicada en el distrito de Miraflores, en medio de un dinámico barrio residencial y comercial. Es una construcción de adobes que data de entre 200 y 700 d.C., conformada por una

\footnotetext{
${ }^{10}$ El paiche, pirarucú o arapaima (Arapaima gigas), es uno de los peces más grandes de agua dulce.

${ }^{11} \mathrm{O}$ sargo.

${ }^{12}$ Carta actualmente descontinuada.
} 
pirámide de 25 metros de altura y un conjunto de patios, recintos y plazas. El sitio es estudiado, conservado y restaurado desde 1981 por un equipo de investigadores apoyado por el Ministerio de Cultura y la Municipalidad de Miraflores. La Huaca Pucllana es uno de los principales atractivos turísticos de Lima. Desde 2003, la cocina del restaurant homónimo es dirigida por la chef Marilú Madueño, quien también es socia del negocio. Marilú pertenece a una familia de clase acomodada de Lima. Tras completar su escolaridad en el colegio más costoso y prestigioso de la ciudad, siguió estudios de hotelería en Estados Unidos y Lima. Los cursos de cocina fueron los que más le interesaron, tanto así que luego viajó a París para especializarse en Le Cordon Bleu. Marilú es una de las pocas representantes femeninas de la cohorte de chefs que lideraron los inicios del boom gastronómico peruano. Cuenta que la idea inicial era que el restaurante se vea como una antigua hacienda - como las había en Lima y la costa peruana en tiempos coloniales y republicanos hasta la reforma agraria - y que la carta sea "peruana". El restaurante tuvo éxito desde sus inicios, pues siempre tuvieron como público a los turistas extranjeros que visitan el recinto arqueológico. Marilú cuenta que, a principios de los 2000, tener un restaurante de este tipo era algo novedoso y que, en ese entonces, no había en Lima tantos restaurantes como los hay hoy. Con el paso del tiempo el negocio fue creciendo y sus espacios se fueron ampliando. Hoy, Huaca Pucllana es muy solicitado para acoger recepciones, encuentros familiares, brindis de honor y cenas corporativas. La combinación entre la vista nocturna desde la gran terraza hacia la pirámide iluminada y una cocina peruana de alto nivel se convierte en un argumento difícilmente superable por otros locales. Marilú también recibe ofertas para impartir clases o talleres culinarios, pero no las acepta todas para no desviarse de su principal línea de negocio que es el restaurante.

Buena parte de la clientela está compuesta por comensales extranjeros. Pueden ser turistas que visitan la huaca y luego se quedan a comer, turistas gastronómicos llevados por turoperadores y cuya prioridad es conocer la cocina local y nuevos sabores, o extranjeros de paso por el Perú y llevados por amistades peruanas preocupadas por obsequiarles una "experiencia completa", según Marilú, "una experiencia entre la vista (de la huaca), la cultura, la comida peruana".

La chef afirma que su clientela tiene un peso fundamental en la construcción de su carta, que define como "peruana-contemporánea" y diferente de aquella de los inicios del restaurant, que era más "tradicional". Explica que Huaca Pucllana no trata de hacer una cocina "súper moderna", "vanguardista" o "deconstruída", como la que practican algunos chefs peruanos de élite, pero una cocina acorde con "nuestros tiempos". No sirve platos muy "deconstruídos" porque prefiere que 
la estructura "peruana" de los platos sea identificable o reconocible, pues al fin y al cabo los turistas buscan algo auténtico. Sin embargo, muchos de los platos típicamente "peruanos" que estaban anteriormente en las páginas centrales de la carta están hoy en las páginas finales, en un apartado llamado "Tradición peruana”. Esta sección cuenta con siete platos de la cocina conocida como criolla peruana: están el lomo saltado, el chupe de pescado, el ají de gallina, el rocoto relleno, el cau-cau, la sábana de lomo con tacu-tacu y el arroz con pato (que aquí presenta una modificación respecto a la receta habitual, pues el arroz está cocinado a modo de risotto) $)^{13}$. Marilú dice que estos platos son inamovibles, tanto de la carta como en su preparación. El apartado más extenso de la carta, que se podría llamar "cocina peruana de autor", es el que se renueva constantemente e integra las evoluciones que se han ido dando en la cocina peruana durante las últimas décadas. Una de ellas consiste en suavizar sabores:

Antes nos centrábamos mucho en los sabores de limón, ají, culantro (cilantro); todo era ácido y picante y un poco fuerte. Y es lo que nos gusta [...]. Ahora la cocina ha virado un poco a que no sea como que solo la cocina criolla es la cocina peruana. En esta carta yo tengo un plato que, si bien no es de cocina peruana, para mí la representa mucho, y es uno de los que más se vende acá. Es una corvina en costra de quinua roja. Entonces está la corvina, que es un pescado que usamos mucho en Perú, está la quinua roja, que... bueno, es un ingrediente que compartimos con muchos países de América pero que también es nativo de acá, le pongo un puré cremoso de papa amarilla y tenemos un saltadito de espárragos y alcachofa que en este país se producen mucho y de calidad extraordinaria, aunque los peruanos no comemos mucho. Entonces, ese plato no tiene picante, no tiene culantro, no tiene limón, no tiene ningún sabor criollo del que dirías "me puede caer mal". Es un plato sencillo. Sin embargo, yo lo considero un plato de mi cocina, y de cocina peruana porque lo comerías mejor en este país que en otro. Porque no hay papa amarilla para el puré, porque la calidad de los espárragos y las alcachofas no son iguales en todos lados, porque el pescado lo consigues acá, igual la quínoa, etc. Es un plato del que no te puedo decir que es de cocina peruana, pero vamos por ahí. Yo creo que la cocina peruana contemporánea es usar ingredientes peruanos de una manera diferente a las que se han venido usando hasta ahora.

Con el paiche, pescado amazónico, sucede algo similar. Marilú lo sirve con una salsa "tipo chimichurri" con cocona ${ }^{14}$ y ají (pimiento) dulce de la selva, minuciosamente mezclados para crear una salsa armónica, no muy ácida y con un leve punto de picante. Con ello logra sabores amazónicos sutiles. Para ella, el control de las salsas es esencial.

Los turistas extranjeros tienen incidencia en la oferta reciente del restaurant, sobre todo cuando ponen de manifiesto nuevos hábitos alimentarios. Marilú tiene

\footnotetext{
${ }^{13}$ Cf. Carta de Huaca Pucllana: http://www.resthuacapucllana.com/es/carta/los-favoritos-de-la-tradicion-peruana.

${ }^{14}$ Solanum sessiliflorum: especie fanerógama originaria de Sudamérica tropical y perteneciente a la familia Solanaceae. Da un fruto de sabor agradable con el que se elaboran, jugos, néctares y dulces.
} 
predefinidos cuatro propuestas de menú para grupos grandes, que arma según el éxito de ventas de los platos y su gusto personal. Intenta que cada cliente reciba un poco de todo: algo del mar, algo de carne, algo de vegetales. Sin embargo, la tarea se complica cuando la lista de comensales indica restricciones alimentarias, ya sea por alergias o convicciones personales: "hace diez años por ahí te tocaba un celiaco, por ahí un intolerante a la lactosa, ahora si te dan una lista de veinte viajeros uno es vegetariano, uno no toma leche, otro es alérgico a las nueces, gluten no come nadie... así es". Huaca Pucllana ya cuenta con menús para celiacos y veganos, sin embargo, a Marilú no deja de sorprenderle el porcentaje de comensales que declaran alergias. Muchos de esos casos deben ser por sugestión individual, piensa.

\section{POSTRE: ¿PATRIMONIOS A LA CARTA?}

¿Cuáles son las relaciones entre estos cuatro tipos de cocina y restaurante con la noción de patrimonio alimentario en su acepción más amplia, cotidiana u ordinaria? ¿A qué ideas remite la cocina patrimonial y qué tipo de objetivos cumple?

La cocina de Pedro remite al ideal culinario doméstico que se reproduce de manera idéntica. Es el sentimiento de comer como en casa lo que los clientes persiguen y lo que los restauranteros ofrecen. Existe entonces una adecuación entre las expectativas de consumo y la experiencia ofrecida. Los platos deben recordar al hogar, a la madre que cocina, a los sabores aprendidos tempranamente en casa. Por esta razón las recetas no cambian o no admiten cambios bruscos. Pedro prepara las recetas que su clientela conoce y desea. No hay necesidad de tomar riesgos. De hecho, él y su esposa tampoco tienen los medios para siquiera intentarlo. Si a su comida se le puede atribuir una dimensión patrimonial - en el sentido que se trata de platos conocidos por la mayoría y prácticamente inmutables en el tiempo - es más por defecto que por voluntad de los restauranteros.

Lo cocina de Centolla se sitúa en la historia de las migraciones de la primera mitad del siglo XX, cuando los flujos de personas procedentes de Europa y de Asia se consolidaron en el territorio peruano, concretamente en Lima. Para los dueños y el chef del restaurante, la "cocina fusión" peruano-japonesa les permite afirmar - de manera simbólica, cultural y económica - su pertenencia al Perú y su adscripción a los mundos de socialización nikkei y peruano (Takenaka, 2017). Esta afirmación de la identidad coincide con el discurso "oficial" de los promotores de la gastronomía peruana, en el que se presenta a esta última como un reflejo de una sociedad fusionada de modo armonioso, como un crisol de culturas 
o una suma de tradiciones, todas equivalentes (García, 2013; Matta, 2014). Entendida así, la sociedad, cultura y cocina nikkei tienen su lugar asegurado dentro de la nación peruana. Pero como la identidad nunca es inocente, es importante destacar que posicionarse como nikkei le permite al negocio sobrevivir en un segmento del mercado sofisticado y competitivo en el que no tiene ninguna ventaja real. Ser nikkei les da mejor resultado que, por ejemplo, exudar algo de nacionalismo al exaltar las cualidades de la centolla capturada en el mar peruano frente a aquella capturada en el mar chileno, que sin embargo fue la apuesta original del restaurante.

La cocina de Pescados Capitales se basa en la innovación culinaria permanente. Clásicos de la cocina marina "criolla" como los cebiches, tiraditos, causas de atún y de pulpo comparten carta con versiones inspiradas en cocinas y técnicas venidas de fuera, principalmente de Asia e Italia. Como en Centolla, las referencias a las migraciones de inicios de siglo XX son claras y, en ese sentido, Pescados Capitales puede ser considerado un representante más de la idea establecida de la cocina peruana como "fusión de culturas". No obstante, Alejandro rechaza que se hable de "cocina fusión". El intenta desmarcarse de esta tendencia creando sabores que denomina como "populares". Esta interpretación de lo popular tiene menos que ver con los gustos o prácticas de consumo de las clases populares (que no pueden pagar una comida en ese restaurant) que con el hecho de que dé lugar a una cocina reconocible, entendible y disfrutable por buena parte de la población (o por aquella que puede permitirse ser cliente). Lo popular son los sabores conocidos, lo divertido, lo informal, los juegos de palabras que hacen referencia a lo cotidiano, lo religioso, al amor y a la sexualidad. En esta configuración, la dimensión patrimonial tiene muy poco que ver con la construcción de un objeto cultural delimitado y determinado: comer lo "tradicional" o lo "auténtico" no es un fin en sí mismo. Por el contrario, la cocina de Pescados Capitales funciona como una mercancía cultural irrestricta, subjetiva e imaginaria que evoca un universo de sentidos supuestamente conocido y compartido por (casi) todos.

En Huaca Pucllana la dimensión patrimonial se expresa a través de tensiones entre "lo tradicional" y lo moderno - lo emergente e innovador. Estas tensionas son propias de un contexto marcado por el turismo. La "tradición peruana" es percibida como algo innegociable y prácticamente fijo en el tiempo, mientras "lo global" acepta cambios, innovaciones y asume riesgos (pues se trata de convencer a foráneos). Esta dualidad se expresa en una carta dividida en dos secciones. La primera ofrece una cocina "peruana-contemporánea", en palabras de Marilú: una cocina con ingredientes locales abierta a la experimentación e innovación, condi- 
ción indispensable para sobrevivir en el negocio de la alta cocina, cuyos códigos y referencias están sujetos a modas y tendencias alimentarias sobre las cuales los chefs (salvo contadas excepciones) tienen poco control. La segunda sección se dirige a "quienes les gusta súper criollo". Este énfasis en lo criollo sugiere que la posibilidad de diálogo con elementos externos sea improbable y hasta no deseable. En efecto, salvo la preparación del arroz con pato tipo risotto, que se hace con el objetivo de suavizar el sabor del cilantro, los sabores conocidos como "criollos" son reproducidos mediante recetas que han sufrido modificaciones mínimas a través del tiempo (Zapata, Zapata, 2019) y componen un gusto interiorizado por los peruanos o, más precisamente, por los limeños. La sección "tradición peruana" podría considerarse como una construcción patrimonial destinada a proteger producciones culturales (recetas) en su singularidad; a proteger lo auténtico de la lógica de la mercantilización y de la equivalencia. Mientras, la sección "peruana-contemporánea" abre la puerta a otro tipo de discursos, recursos e intereses. En suma, la carta de Huaca Pucllana refleja sobre todo su condición de restaurant turístico y gastronómico y, en ese sentido, está obligada a responder a una doble y altísima exigencia.

En base a lo anterior, podemos afirmar que la relación entre patrimonio alimentario y la cocina producida en restaurantes es ambigua e instrumental. Se puede observar que la dimensión patrimonial, si bien presente y central en muchos casos, nunca es explícita en términos lingüísticos ni culturales ni políticos. Todo parece indicar que los restaurantes no están hechos para salvaguardar patrimonio. Las cocinas presentadas arriba son mercancías que se nutren de representaciones culturales movilizadas por los dueños de negocios y los cocineros, y son destinadas principalmente a justificar su actividad y asegurar sus medios de supervivencia. Las referencias a lo tradicional, lo auténtico, lo conocido o lo familiar tienen, en todos los casos, un carácter estratégico. En este sentido, "lo patrimonial" adquiere significados distintos según la agenda del restaurante y el acceso diferenciado de los dueños a recursos económicos, sociales, y culturales.

Para Pedro y su esposa, vender menús considerados clásicos ("criollo", "mariscos" y chifa") a un precio muy asequible y en un ambiente de comensalía "como en casa" les permite hacer un uso eficiente de los recursos a su disposición para alcanzar una relativa estabilidad económica. Aquello repercute en su cocina, también estable pues casi no admite transformaciones de las recetas "caseras". Para los Sueyoshi, su acercamiento al patrimonio se realizó mediante una afirmación de sus orígenes japoneses, que plasmaron en la carta de su restaurant y coinciden con la moda de los makis. Aquella estrategia le está permitiendo a Centolla sobrevivir, más mal que bien, en un mercado muy competitivo. Centolla ha tenido 
que cerrar definitivamente sus puertas en Miraflores, distrito convertido en un campo de batalla entre negocios gastronómicos, y abrirlas en Jesús María, un distrito de clase media-baja central y dinámico, pero muy venido a menos en las últimas tres décadas. Los juegos sobre la tradición y lo popular expresados en su carta consolidaron a Pescados Capitales como uno de los mejores restaurantes de comida marina del país, según las guías de restaurantes y la prensa especializada. Hoy cuenta con dos locales más, en distritos dinámicos de clase media: Surco y San Borja. Por su parte, la "doble carta" de Marilú, que representa por un lado lo tradicional y por el otro lo moderno, ha permitido a Huaca Pucllana convertirse como el restaurante turístico de alto nivel por antonomasia.

Visto esto, parece razonable pensar que la patrimonialización a la que las cocinas "nacionales" y prácticas alimentarias están siendo sometidas mediante esfuerzos institucionales tendrá muy poca o ninguna incidencia en la cocina de restaurantes y en las cocinas patrimoniales. ¿Qué cambios ocurrirían en la comida de los restaurantes de Perú si la UNESCO declara, por ejemplo, la "cocina tradicional peruana" como patrimonio cultural inmaterial? Probablemente pocos o ninguno. Lo que sí se puede prever es la utilización por parte de restauranteros de la "etiqueta" UNESCO como medio de promoción de sus locales, que algún negocio "invente una tradición", como ya ocurrió en otros lugares (Brulotte, Starkman, 2014; Suremain, 2017) y la apertura de restaurantes motivados por el reconocimiento global de la cocina peruana. En una lógica opuesta, uno podría imaginar el surgimiento de una cocina patrimonial "rival", un "patrimonio insurgente" (Novoa, 2018) que compita con la cocina patrimonial "oficial" o "autorizada". Pero el cambio dentro de una cocina es más difícil de imaginar y cuantificar. El hecho de que la UNESCO y los gobiernos nacionales no tengan injerencia real en la oferta de los restaurantes, que son, al fin y al cabo, iniciativas privadas, no debería dar lugar a preocupaciones sobre una posible estandarización, anquilosamiento o congelamiento de las cocinas y prácticas alimentarias. El competitivo mercado gastronómico y la diversidad cultural hecha mercancía se encargarán de mantener la vitalidad y flexibilidad de las cocinas. Queda entonces las preguntas, ¿para qué sirve el patrimonio alimentario? Y ¿a quién le sirve? Contestarlas probablemente nos aleje de los restaurantes y sus cocinas y nos lleve a dos mundos distintos: por un lado, al de los gobiernos, las corporaciones y las industrias culturales y, por otro lado, al mundo rural, donde productores agrícolas y comunidades campesinas están enfrascados en luchas por la representación política y la obtención de mejores condiciones de vida. En aquellos mundos, el patrimonio alimentario adquirirá otro significado. 


\section{BIBLIOGRAFÍA}

Bak-Geller, S., Matta, R., Suremain, C.-E. de. (2019). Patrimonios alimentarios: Entre tensiones y consensos. San Luis Potosí, México: El Colegio de San Luis; París, Francia: IRD Editions.

Beriss, D., Sutton, D. (2007). Starter: Restaurants, Ideal Postmodern Institutions. En D. Beriss, D. Sutton (eds.), The Restaurant Book (pp. 1-15). Oxford, Reino Unido: Berg. https://doi.org/10.5040/9781350044913_0006

Bestor, T. (2004). Tsukiji: The Fish Market at the Center of the World. Berkeley: University of California Press.

Brulotte, R. L., Di Giovine, M. (2014). Edible Identities. Food as Cultural Heritage. Farnham, Reino Unido: Ashgate.

Brulotte, R. L., Starkman, A. (2014). Caldo de Piedra and Claiming Pre-Hispanic Cuisine as Cultural Heritage. En R. L. Brulotte, M. Di Giovine (eds.), Edible Identities. Food as Cultural Heritage (pp. 109-123). Farnham, Reino Unido: Ashgate. https://doi.org/10.4324/9781315578781-8

Caldwell, A. (2011). Will Tweet for Food. The Impact of Twitter and New York City Food Trucks. En P.-W. Forson, C. Counihan (eds.), Taking Food Public: Redefining Foodways in a Changing World (pp. 306-321). Nueva York, NY: Routledge.

Comaroff, J. L., Comaroff, J. (2009). Ethnicity Inc. Chicago, IL: University of Chicago Press. https://doi.org/10.7208/chicago/9780226114736.001.0001

Consiglieri, N. (2019). Integradora y excluyente: El rol de la gastronomía en la Urbanización Santa Cruz (Lima, Perú). Anthropology of Food, (14). https://doi.org/10.4000/aof.10031

DeSoucey, M. (2010). Gastronationalism: Food Traditions and Authenticity Politics in the European Union. American Sociological Review, 75(3), pp. 432-455. https://doi.org/10.1177/0003122410372226

Ferguson, P. (2010). Culinary Nationalism. Gastronomica, 10(1), pp. 102-109. https://doi.org/10.1525/gfc.2010.10.1.102

Fonseca, V. (2005). Nuevo Latino: Rebranding Latin American Cuisine. Consumption Markets \& Culture, 8(2), pp. 95-130. https://doi.org/10.1080/10253860500112826

García, M. E. (2013). The Taste of Conquest: Colonialism, Cosmopolitics, and the Dark Side of Peru's Gastronomic Boom. The Journal of Latin American and Caribbean Anthropology, 18(3), pp. 505-524. https://doi.org/10.1111/jlca.12044

Hassoun, J.-P. (2010). Deux restaurants à New York: l'un franco-maghrébin, l'autre africain. Anthropology of Food, (7). https://doi.org/10.4000/aof.6730

Hassoun, J.-P. (2014). Restaurants dans la ville-monde. Douceurs et amertumes. Ethnologie française, 44(1), pp. 5-10. https://doi.org/10.3917/ethn.141.0005

Henderson, J., Si Yun, O., Poon, P., Biwei, X. (2012). Hawker centres as tourist attractions: The case of Singapore. International Journal of Hospitality Management, 31(3), pp. 849-855. https://doi.org/10.1016/j.ijhm.2011.10.002

Hernández, A., Andreeva, S. (2016). ¿Mercados, museos o malls? La gentrificación de los mercados municipales en Barcelona y Madrid. EntreDiversidades: Revista de Ciencias Sociales y Humanidades, (6), pp. 143-173. https://doi.org/10.31644/ED.6.2016.a05

Hobsbawm, E., Ranger, T. (1983). The Invention of Tradition. Cambridge, Reino Unido: Cambridge University Press. 
Ichijo, A., Ranta, R. (2016). Food, National Identity and Nationalism. Basingstoke, Reino Unido: Palgrave Macmillan. https://doi.org/10.1057/9781137483133

INEI (2014). Una mirada a Lima Metropolitana. Lima, Perú: Instituto Nacional de Estadística e Informática.

Isnart, C. (2012). Les patrimonialisations ordinaires. Essai d'images ethnographiées. ethnographiques.org, (24). Recuperado de https://www.ethnographiques.org/2012/Isnart

Katz, E., Lazarsfeld, P. (1955). Personal Influence. Nueva York, NY: The Free Press.

Long, L. (2004). Culinary Tourism. Lexington: The University Press of Kentucky.

López-García J., Mariano Juárez, L., Medina, X. (2017). Usos y significados contemporáneos de la comida desde la antropología de la alimentación en América Latina y España. Disparidades. Revista de Antropología, 71(2), pp. 327-370. https://doi.org/10.3989/rdtp.2016.02.001

Matta, R. (2013). Valuing Native Eating. The Modern Roots of Peruvian Food Heritage. Anthropology of Food, (S8). https://doi.org/10.4000/aof.7361

Matta, R. (2014). República gastronómica y país de cocineros: comida, política, medios y una nueva idea de nación para el Perú. Revista Colombiana de Antropología, 50(2), pp. 15-40. https://doi.org/10.22380/2539472X45

Matta, R. (2016). Food incursions into global heritage: Peruvian cuisine's slippery road to UNESCO. Social Anthropology, 24(3), pp. 338-352. https://doi.org/10.1111/14698676.12300

Matta, R. (2019). Mexico's ethnic culinary heritage and cocineras tradicionales (traditional female cooks). Food and Foodways, 27(3), pp. 211-231. https://doi.org/10.1080/07409710.2019.1646481

Matta, R., García, M. E. (2019). The Gastro-Political Turn in Peru. Anthropology of Food, (14). https://doi.org/10.4000/aof.9970

May, S., Sidali, K., Spiller, A., Tschofen, B. (2017). Taste | Power | Tradition. Geographical Indications as Cultural Property. Göttingen, Alemania: Universitätsverlag Göttingen. https://doi.org/10.17875/gup2017-1004

Medina, F. X. (2017). Reflexiones sobre el patrimonio y la alimentación desde las perspectivas cultural y turística. Anales de antropología, (51), pp. 106-113. https://doi.org/10.1016/j.antro.2017.02.001

Medina, F. X., Leal, M. P., Vázquez-Medina, J. A. (eds.). (2018). Tourism and Gastronomy (Special Issue). Anthropology of Food, (13). https://doi.org/10.4000/aof.8800

Novoa, M. (2018). Insurgency, heritage and the working class: the case of the Theatre of Union $\mathrm{N}^{\mathrm{O}} 6$ of the Coal Miners of Lota, Chile. International Journal of Heritage Studies, 24(4), pp. 354-373. https://doi.org/10.1080/13527258.2017.1378904

Parasecoli, F. (2017). Knowing Where it Comes From. Labeling Traditional Food to Compete in a Global Market. Iowa City, IA: University of Iowa Press. https://doi.org/10.2307/j.ctt20q23qh

Pilcher, J. (2012). Planet Taco: A Global History of Mexican Food. Oxford, Reino Unido: Oxford University Press.

Ray, K. (2016). The Ethnic Restaurateur. Londres, Reino Unido: Bloomsbury. https://doi.org/10.5040/9781474269414 
Sammells, C. (2014). Haute traditional cuisines: how UNESCO's list of intangible heritage links the cosmopolitan to the local. En R. L. Brulotte, M. Di Giovine (eds.), Edible Identities. Food as Cultural Heritage (pp. 141-158). Farnham, Reino Unido: Ashgate. https://doi.org/10.4324/9781315578781-10

Suremain, C.-E. de. (2017). Cuando la alimentación se hace patrimonio. Rutas gastronómicas, globalización y desarrollo local (México). TRACE, (72), pp. 165-181. https://doi.org/10.22134/trace.72.2017.114

Takenaka, A. (2017). Immigrant integration through food: Nikkei cuisine in Peru. Contemporary Japan, 29(2), pp. 117-131. https://doi.org/10.1080/18692729.2017.1351022

Tholstrup Hermansen, M. E. (2012). Creating Terroir. An Anthropological Perspective on New Nordic Cuisine as an Expression of Nordic Identity. Anthropology of Food, (S7). https://doi.org/10.4000/aof.7249

Tibère, L., Bessière, J. (eds.). (2011). Patrimoines alimentaires [número temático]. Anthropology of Food, (8). Recuperado de http://aof.revues.org/6758

Timothy, D. (2015). Heritage Cuisines: Traditions, Identities and Tourism. Londres, Reino Unido: Routledge. https://doi.org/10.4324/9781315752525

Trubek, A. (2008). The Taste of Place. Berkeley: University of California Press.

Tsumura, M., Barron J. (2013). Nikkei es Perú. Lima, Perú: Telefónica del Perú.

Zapata, S., Zapata, J. (2019). Principios y redes del sabor en la cocina criolla peruana de fines del siglo XIX. En S. Bak-Geller, R. Matta, C.-E. de Suremain (eds.), Patrimonios alimentarios: Entre tensiones y consensos. San Luis Potosí, México: El Colegio de San Luis; París, Francia: IRD Editions. 